\title{
Repensar la historia diplomática: diálogos, ausencias y retos para el entendimiento de la alteridad histórica mundial
}

\author{
Gabriel Andrés Arévalo Robles*
}

\begin{abstract}
ReSUMEN
El presente artículo pretende señalar las limitaciones de las teorías dominantes de las Relaciones Internacionales sobre el entendimiento histórico de la diplomacia, y la normalización hecha de las bases categoriales sobre las que es interpretada la alteridad histórica mundial, la cual invisibilizó actores, saberes y prácticas diplomáticas que perviven en la exterioridad del sistema mundial. Para respaldar las afirmaciones del texto, se aportan hechos históricos de la actividad diplomática que dan cuenta tanto de la resistencia histórica como del entendimiento político y diplomático mundial. En su conjunto, se suma a la promoción de las agendas de investigación sobre diplomacia, interesadas en comprender mejor la alteridad planetaria y su preocupación por la transformación de la violencia y la dominación global.
\end{abstract}

\section{Palabras clave}

Diplomacia; historia relaciones internacionales; sistema mundo.

\section{TITLE}

Rethinking diplomatic history: dialogues, absences and challenges to understand global historical otherness

\begin{abstract}
This paper seeks to identify the limitations of mainstream International Relations theories about the historical understanding of diplomacy, and the normalization of the parameters used to interpret world historical otherness, which invisibilized actors, knowledge and diplomatic practices that survive outside the world system. For this purpose, the paper outlines historical facts of diplomatic activity that account for historical resistance as well as for global political and diplomatic understanding. Overall the paper aims to contribute to the research agendas on diplomacy, interested in better understanding planetary otherness and its concern for the transformation of violence and global domination.
\end{abstract}

\section{KeYWORDS}

Diplomacy; history of international relations; world system.

\section{* Gabriel Andrés} ARÉVALO ROBLES, Director de la Unidad para el Desarrollo, Ciencia y la Innovación, Facultad de Derecho UAN-Boyacá, Colombia. PhD en Estudios Internacionales de la Universidad del País Vasco/Euskal Herriko Unibertsitatea. Maestrías: Máster de Estudios Internacionales de la (UPV/EHU); Máster en Cooperación Internacional Descentralizada: Paz y Desarrollo. Análisis y Gestión de la Agenda Global en el marco del Sistema de las Naciones (UPV/EHU). Pregrados: Sociólogo de la Universidad Nacional de Colombia y Abogado de la Universidad Libre.

\section{Recibido:}

10-09-2017

Aceptado:

11-01-2018

DOI:

http://dx.doi.org/ $10.15366 /$ relacionesinternacionales2018.37.005 


\section{ntroducción}

El presente artículo pretende incursionar brevemente en las discusiones teóricas e históricas dominantes de la diplomacia. Dentro y fuera de la práctica académica, las conceptualizaciones sobre diplomacia han sido bastante limitadas, y muchas de las veces insuficientes y desestimulantes para promover agendas de investigación que tomen en cuenta la actividad diplomática de los actores subalternos. En pocas ocasiones se ha considerado que la diplomacia sea una práctica y una noción promovida por pueblos indígenas, sociedad civil, movimientos sociales, partidos políticos, y otros actores, apenas nombrados marginalmente en la teoría de las relaciones internacionales. Sin embargo -aunque a menudo imitan la clásica diplomacia estatal- una pluralidad de actores han desarrollado una determinante actividad transfronteriza por medio de prácticas diplomáticas aun ocultas en los manuales de curso. Dichas expresiones, pocas veces consideradas con seriedad, forman parte de la diplomacia global actual y, sobre todo, de la historia diplomática que contribuyó a dar forma al sistema mundial.

En su corta historia subdisciplinar, la diplomacia ha sido limitada a la política exterior del Estado ${ }^{1}$, al arte de conducir o gobernar las relaciones interestatales ${ }^{2}$, a las negociaciones de entidades nacionales de carácter independiente ${ }^{3}$, al "refugio de redundante aristocracia"4, o a la habilidad profesional y saber especializado de códigos jurídicos, políticos, protocolarios y conocimientos culturales y económicos relacionados con el interés nacional. Una de las principales razones de esta reducida mirada ha sido su dependencia de las clásicas teorías de las Relaciones Internacionales que en los siglos XX y XXI fue dominada por académicos anglosajones, europeos $y$, en menor medida, por australianos, y que trataban sobre relaciones y temáticas que preocupan a las potencias y a los actores hegemónicos de la economía y la política global; ocurrió que, de forma predominante, debido al curso de los acontecimientos de la historia de americanos y europeos, se reprodujeron en este campo los silencios del pensamiento y la invisibilización del protagonismo de otros actores del mundo no-occidental ${ }^{5}$.

Este vacío de análisis obliga a buscar una posición histórica y teórica que cuestione el relato eurocéntrico que da forma a la historia universal de la diplomacia, intento que desarrollaré tomando como referencia la conexión del mundo atlántico desde 1492 y, en particular, desde la experiencia americana como ejemplo de dicha exclusión ${ }^{6}$. Para ello, este artículo asume la definición de diplomacia promovida por James Der Derian, quien la

\footnotetext{
${ }^{1}$ KISSINGER, Henry, Diplomacy, Simon \& Shuster, Nueva York, 1994. Ver otras definiciones similares en la exposición de JÖNSSON, Christer, "Theorising Diplomacy" en MCKERCHER Brian J. C. (ed.), Routledge Handbook of Diplomacy and Statecraft, Routledge, Londres, 2011.

2 ROSECRANCE, Richard, "Diplomacia" en Enciclopedia Internacional de Ciencias Sociales, Aguilar, Madrid, 1974.

3 WATSON, Adam, Diplomacy: The Dialogue Between States, Psychology Press, Londres: 1982.

4 JONES, Raymond, The British Diplomatic Service, 1815-1914, Wilfrid Laurier University Press, Ontario, 1983.

5 JONES, Branwen Gruffydd (ed.), Decolonizing International Relations, Rowman \& Littlefield, Maryland, 2006.

${ }^{6}$ El presente artículo no persigue reemplazar un esencialismo eurocéntrico por un esencialismo americanista. Usa la experiencia americana porque reconoce que el pensamiento tiene un lugar de producción pero no pretende universalizar dicha experiencia para narrar toda la historia mundial. Por el contrario, la usa como ejemplo para demostrar que la noción de diplomacia moderna contada desde la academia occidental inventó un molde para adecuar sus actores e instituciones y dar un estatus de superioridad a dicha noción, a la vez que dejó fuera otras experiencias de alteridad. También se interesa el artículo por delimitar un momento histórico particular de la diplomacia - la formación del sistema mundo moderno-, porque los autores hegemónicos han dado preeminencia a la diplomacia estatal moderna y europea como la "definitiva y perfeccionada diplomacia", negando o invisibilizando el resto de tipos de diplomacia.
} 
considera como "la mediación del extrañamiento entre individuos, grupos o entidades"7 por su amplia y dinámica posibilidad de encuadre fenomenológico de las prácticas diplomáticas históricas. Aspecto que resalta Noé Cornago, en una interpretación de la obra de Der Derian, al reflexionar que:

"En su exploración de la diplomacia, Der Derian (1987) sugiere que cualquiera que sea el locus político que consideremos es a partir del proceso de extrañamiento con el otro, y de la evolución de las condiciones sociales en que éste se produce, que surge el comportamiento que se irá conformando históricamente, no sin importantes tensiones, como diplomático. Ese impulso diplomático se distingue por gestionar la diferencia entre grupos humanos mediante un conjunto de prácticas, instituciones y discursos -envueltos siempre en la ambigüedad- que afirman simultáneamente, al menos de manera tentativa, una cierta identidad entre las partes - fundamentada en el reconocimiento mutuo de la capacidad de interlocución entre iguales que la propia diplomacia misma viene a su vez a configurar- y la diferencia insalvable que define los contornos -ya sean jurisdiccionales, territoriales, o culturales- del grupo al que cada parte dice, respectivamente, representar"8.

En consecuencia, el objetivo del artículo es el siguiente: aportar visiones críticas que tomen en cuenta fenómenos que dieron forma y contenido al sistema mundial moderno pero que fueron relegados por el relato oficial diplomático. Esta perspectiva debería ofrecernos tentativamente, al menos- una historia diplomática más rica y menos marginal del papel que pueblos y naciones ancestrales (estados-subordinados ${ }^{9}$ ), grupos sociales, y actores sociales y políticos jugaron y juegan en la producción de la interacción planetaria. Para desarrollar mejor estas afirmaciones, el presente documento trabajará en dos niveles: en el primero, echará una mirada a la postura de los teóricos de las relaciones internacionales y conversará críticamente con ellos, mostrando nuevas disquisiciones académicas en el campo diplomático, y en el segundo nivel, reconstruirá breves momentos históricos tanto del nacimiento de la diplomacia moderna como de prácticas diplomáticas recientes, para dar cuenta de la riqueza diplomática invisibilizada por los relatos históricos y teóricos oficiales.

\section{Una mirada crítica a los teóricos hegemónicos de la diplomacia}

Advierte Christer Jönsson que los principales desarrollos sobre diplomacia provienen de las escuelas del realismo, el institucionalismo liberal y los enfoques postmodernos ${ }^{10}$. De los dos primeros enfoques proviene lo que se denomina la "versión dominante de la diplomacia", básicamente, alimentada por un espíritu eurocéntrico del conocimiento y una concepción anárquica, negativa e interestatal del sistema mundial.

Desde el principio de la disciplina, la diplomacia se basó en la consideración negativa

\footnotetext{
7 DER DERIAN, James, On Diplomacy: A Genealogy of Western Estrangement, Blackwell, Oxford, 1987.

8 CORNAGO, Noé, "Diplomacia como heterología".

9 Es necesario destacar que algunos estados subordinados o dependientes han desarrollado en ocasiones, actividades diplomáticas de pretenden enfrentar a las potencias (o matizar su dominación) desde una particular actividad diplomática. Aunque no lo podemos desarrollar aquí en profundidad, por momentos las ligas africanas, o algunos estados latinoamericanos como Bolivia o Ecuador, por ejemplo, han desarrollado una diplomacia crítica que llamaremos acá "desde abajo", emulando la diplomacia clásica.

${ }^{10}$ JÖNSSON, Christer, Theorising Diplomacy..., op.cit.
} 
sobre la naturaleza humana y sus pasiones propias de la teoría hobbesiana. En la obra Política entre las naciones, de Hans Morgenthau, el autor enlazó el destino de la diplomacia al del estado, y con ello al interés nacional y la lucha por el poder. Morgenthau observó la diplomacia como una extensión de la influencia política que ofrece la guerra, de manera que "la conducción de los asuntos exteriores de una nación por parte de los diplomáticos es para el poder nacional durante tiempos de paz, lo mismo que las estrategias y tácticas de los líderes militares en tiempos de guerra"11. Así lo entiende Hans Morgenthau:

"Si hubiera alguna forma para desterrar la lucha por el poder en el escenario internacional, la diplomacia desaparecería. Si el orden, la anarquía, la paz y la guerra no fuesen asuntos que les incumbieran a las naciones del mundo, ellas podrían prescindir de la diplomacia, prepararse para la guerra y esperar lo mejor"12.

En la versión renovada del realismo político ofrecida por Kenneth Waltz, la diplomacia perdió relevancia como enfoque de análisis y apareció "como un factor contingente sobre el que ni es posible, ni necesario teorizar"13. Las habilidades diplomáticas son desde esta perspectiva un epifenómeno visto desde la teoría de Waltz y confirmado por el desinterés de los autores neorrealistas sobre el estudio de la diplomacia ${ }^{14}$.

La otra versión hegemónica de la diplomacia es la proveniente del institucionalismo liberal o transnacionalismo. Promovido por Keohane y Nye, ésta se fundamentó en la cooperación internacional como posibilidad para coordinar las políticas entre los estados dentro de los regímenes internacionales ${ }^{15}$. En este horizonte, la diplomacia "permite a los Estados coexistir pacíficamente e interactuar en ambientes reglados que mejoran las oportunidades para una mutua comunicación y representación entre estados"16. En el marco de esta "plataforma académica" la diplomacia pasa a convertirse en una noción esencial. Martin Wight, considerado uno de los autores de la primera generación del programa de investigación no norteamericano del institucionalismo liberal, consideró la diplomacia como el arte de comunicación entre poderes y al sistema diplomático como una institución de las relaciones internacionales ${ }^{17}$.

Resulta atrayente la afirmación de Wight al considerar el rol de la diplomacia como aquella que difunde las ideas de la Europa occidental hacia el mundo desde los primeros encuentros con los pueblos ancestrales de América. Aun así, esta categoría analítica parece que pierde su riqueza cuando quiere dar un estatus a la diplomacia con la noción de institucionalización de la práctica diplomática de la Europa occidental, pese a considerar en sus argumentos que los mensajeros y los mensajes han estado desde vieja data relacionados a las prácticas de los pueblos. La postura de Wight rompe la idea de alteridad al afirmar que

\footnotetext{
${ }^{11}$ Ibídem, p. 177. [Traducción propia]

${ }^{12}$ Ibíd., p. 627.

${ }^{13}$ SHARP, Paul, Diplomatic Theory of International Relations, Cambridge University Press, Cambridge, 2009.

${ }^{14}$ JÖNSSON, Christer, Theorising Diplomacy..., op.cit.

${ }^{15} \mathrm{KEOHANE}$, Robert, Después de la hegemonía: cooperación y discordia en la política económica mundial, Grupo Editor Latinoamericano, Buenos Aires, 1988.

${ }^{16}$ JÖNSSON, Christer, Theorising Diplomacy..., op.cit., p. 20.

${ }^{17}$ WIGHT, Martin, Power Politics, Continuum, Londres y Nueva York, 2002.
} 
la diplomacia se convierte en una institución del sistema internacional gracias a la Europa moderna que llevó las ideas al mundo mientras el mundo no llegó a Europa. La diplomacia como fenómeno histórico se convierte así en un contrasentido orientado en una sola vía, una comunicación en todo caso extraña si se piensa en los actores, los medios y los mensajes que implica una relación entre dos o más entidades. Desde su ángulo, la historia de la diplomacia solo es entendible como una institución surgida de la experiencia de la Europa cristiana hacia el sistema de estados europeos que luego ilustró al mundo a través de sus prácticas de expansión.

En este mismo sentido podemos observar las ideas de Hedley Bull, reconocido como uno de los más importantes teóricos de la segunda generación de la escuela británica, quien refinó la taxonomía ofrecida por Wight y dio un sentido relevante a la diplomacia en el marco de la cultura. Bull introdujo la noción de cultura diplomática como el conjunto de ideas y valores comunes que poseen los representantes oficiales de los estados ${ }^{18}$, y la diferenció de la cultura política internacional como "la cultura intelectual y moral que determina las actitudes hacia la sociedad de estados en las sociedades que lo forman"19. Bull afirmó que la cultura diplomática en la sociedad internacional contemporánea es una cultura intelectual de élite con los principales rasgos de la modernidad: idiomas comunes, concepciones compartidas de entender el mundo, conceptos y técnicas universales adoptados por los gobiernos del planeta. La cultura diplomática forma parte de la cultura política internacional: "la necesaria precondición para la emergencia de lo que llama la sociedad internacional"20.

Estas ideas de Bull son novedosas al considerar una variable con poca relevancia en este enfoque hegemónico de la diplomacia, sin embargo, se halla limitado por las muchas coincidencias con el realismo y su predominio de noción de poder, instituciones de guerra, grandes potencias, equilibrio de poder y diplomacia ${ }^{21}$. Además, para Der Derian, la división que hizo Bull entre cultura diplomática y cultura política internacional es desafortunada, en vista de que no resulta coherente fraccionar las intenciones subjetivas del diplomático de los aspectos estructurales intersubjetivos de la cultura de la sociedad internacional ${ }^{22}$. En términos más generales, para Iver Neumann y Noé Cornago, las ideas alrededor de la cultura diplomática de Bull fueron poco desarrolladas pese a su potencial planteamiento ${ }^{23}$.

Algo similar se puede entender del trabajo que realiza Adam Watson, uno de los miembros del British Committee, quien afirmó su noción de diplomacia como una práctica social. Watson vio la diplomacia con arraigo histórico y observó que la precondición de la soberanía no es definitiva para que se produzca la diplomacia, la cual define como "la

\footnotetext{
${ }^{18}$ BULL, Hedley La sociedad anárquica: Un estudio sobre el orden en la política mundial. Los Libros de la Catarata, Madrid, 2005, p. 365.

${ }^{19}$ Ibídem, p. 365.

${ }^{20}$ NEUMANN, Iver B. "The English School on Diplomacy" en Theory of Diplomacy, JÖNSON, Christer y LANGHORNE Richard (coords.), Sage Publicaciones, Londres, 2004, p. 96-116. [Traducción propia]

${ }^{21}$ HURRE, Andrew, "Prólogo a la Tercera Edición de 'La Sociedad Anárquica' 25 años después" en BULL, Hedley, La sociedad anárquica..., op.cit.

22 DER DERIAN, James, On Diplomacy: A Genealogy of Western Estrangement, Blackwell, Oxford, 1987.

${ }^{23}$ Afirmaciones de Iver Neumann y Noé Cornago en: NEUMANN, Iver B, "The English School..., op.cit.
} 
negociación entre entidades políticas las cuales reconocen una a la otra su independencia"24 y considera un error limitar el concepto de diplomacia a las embajadas o a los servicios diplomáticos. Sin embargo, y aquí notamos nuevamente el prejuicio eurocéntrico, sugiere que la naturaleza y forma de la diplomacia moderna es una herencia de la experiencia europea y su institucionalización, de la producción histórica que emerge de la formación del sistema de estados europeos ${ }^{25}$.

Más recientemente, Kalevi Holsti se propuso narrar los cambios que han experimentado en los últimos trescientos años las instituciones del sistema internacional, y dar cuenta del propio perfil que cada institución encarna en los cambios históricos de complejización, reversión, obsolescencia o expansión. Holsti considera a las instituciones como una mezcla de prácticas, ideas y normas que pueden dividirse entre instituciones fundacionales e instituciones procesales ${ }^{26}$. La diplomacia, según Holsti, es una institución del sistema internacional donde las funciones esenciales no han cambiado mucho desde el siglo XVII. Las prácticas diplomáticas han venido creciendo en una estandarización y consenso sobre normas de representación, inmunidad, establecimiento de embajadas, burocratización de la administración de las relaciones internacionales y la profesionalización de la carrera diplomática. Esto quiere decir que califica la diplomacia como una práctica profesional y técnica, a la vez que le confiere unos valores y normas formados por la experiencia intraeuropea, sin tener en cuenta otros aspectos históricos.

La diplomacia - para Holsti- cobra relevancia en el sistema internacional como una de las formas comunes de interacción por medio de procedimientos regulados, gobernados por reglas y costumbres, que buscan resolver la mayoría de conflictos entre las unidades políticas. Cuando los gobernantes persiguen sus objetivos y defienden sus intereses buscan la comunicación para impedir, alterar o reforzar ideas, acciones o comportamientos de sus pares. Según Holsti, la rutina diplomática más común entre los gobernantes es el intercambio de visiones, el sondeo de intenciones y el convencimiento a otros actores. En otras ocasiones, la diplomacia persigue crear la ilusión de que un gobierno está interesado en negociar -aun cuando sabe que no desea llegar a ningún acuerdo- con el objetivo de generar un impacto en la opinión pública. Un gobierno podría además entrar en negociaciones diplomáticas con el propósito de promover propaganda, hacer un llamamiento al público y debilitar la posición negociadora de sus oponentes. Sin embargo - concluye Holsti-, estas últimas actuaciones no son las actividades principales de la diplomacia, sino alcanzar convenios, compromisos y acuerdos con la finalidad de organizar esfuerzos colaborativos para enfrentar los desafíos de cada época y situación ${ }^{27}$.

En el trabajo de Holsti podemos ver un esfuerzo de reactualización de las teorías clásicas frente a los retos que ofrecen las transformaciones contemporáneas de la globalización y la actividad transnacional de actores no estatales. Sin embargo, resulta curioso (por la

\footnotetext{
${ }^{24}$ WATSON, Adam. Diplomacy: The Dialogue..., op.cit., p. 33.

${ }^{25}$ Ibídem.

${ }^{26}$ HOLSTI, Kalevi, Taming the Sovereigns: Institutional Change in International Politics, Cambridge University Press, Cambridge, 2004.

${ }^{27}$ Ibídem.
} 
importancia que se le da a la historia diplomática) que ninguna reconozca los aportes que la conexión transatlántica iniciada en 1492 con los viajes de Cristóbal Colón hicieron a la formación de la diplomacia intraeuropea y al establecimiento de la diplomacia europea con el resto del mundo. Hay que reconocer que la formación del pensamiento moderno estuvo influenciada no solamente por las ideas del renacimiento, sino también por el impacto de la conquista y del proceso de colonización sobre la cultura, la economía y la política del colonizador y del colonizado.

El enfoque racionalista tiene problemas por su carácter ahistórico y la confusión sobre la historia y la relación final de los estados con la diplomacia. Waltz, por ejemplo, asevera que las estructuras del sistema internacional se han sostenido iguales por miles de años en todo lugar, lo que equivale a decir que hubo un sistema internacional y de estados antes de que existieran los estados modernos o el mercado internacional; este desprendimiento de la historia conlleva una cierta naturalización del estado como una entidad permanente y lógica en el desarrollo de las sociedades ${ }^{28}$.

A pesar de que algunos autores expuestos consideran la noción de diplomacia como una práctica social -Watson-, anterior al sistema europeo de Estados -Wight-, y con aspectos culturales -Bull-, la encadenan al sujeto estado, a la profesionalización y burocratización de la diplomacia, y a la historia europea. Este tipo de concepción diplomática es reduccionista y elitista y, aunque sus desarrollos teóricos contienen aportes muy interesantes, invisibiliza una parte sustancial de la historia diplomática y la reduce a una limitada concepción de las transformaciones históricas del mundo (la evolución intraeuropea), recurriendo a una visión titulada de la diplomacia (profesional, técnica, burocrática, elegante, táctica, formal), y concentrada en los temas y problemáticas que interesan a un número limitado de estados (seguridad, guerra-paz, ganancias, intereses nacionales, economía política, medio ambiente).

La exposición dominante de las relaciones internacionales y su desarrollo sobre la noción de diplomacia pone sobre nuestro relato la necesidad de explorar visiones alternativas de sus actores, de su relato y de su contenido. Así, se pretende mostrar las posibilidades de la diplomacia como una noción abierta, múltiple y crítica, que ofrezca nuevas opciones en el mapa teórico de la política global.

\section{Aperturas a la noción de diplomacia}

La diplomacia no puede circunscribirse exclusivamente a lo que hacen los estados. Actores no estatales - a menudo emulando la diplomacia clásica- han desarrollado procesos diplomáticos desde sus propias concepciones culturales y sus intereses a lo largo de la historia.

En su reciente trabajo, Cornago considera que una nueva conceptualización de la diplomacia debe ofrecer un campo más amplio de significados e incluir una variedad de actores que puedan equipararse a los diplomáticos oficiales. Sugiere, además, que las transformaciones contemporáneas de la diplomacia pueden ser caracterizadas como un proceso de pluralización:

"Pluralization, after all, operates through countless practices, observable not

\footnotetext{
${ }^{28}$ HALLIDAY, Fred, Las relaciones internacionales en un mundo en transformación, Catarata, Madrid, 2002.
} 
only in the ministerial headquarters, embassies and consulates, but also in an ever-increasing variety of sites, where NGOs activists, local government officials, indigenous leaders, think tanks, media brokers, influential scientists, corporate CEOs, celebrities, part-time terrorists, and even organized criminals, operate with very different purposes and more or less contested legitimacies"29.

El paso de la diplomacia (en singular) a las diplomacias (en plural) constituye un replanteamiento teórico y metodológico para la interpretación de los emergentes fenómenos de la política contemporánea en el marco de las interacciones humanas históricas. Cornago llama la atención sobre su limitado significado, cooptado por la diplomacia estatal, la embajada o el diplomático profesional y su actividad técnica. Por el contrario, afirma que tras estas etiquetas hay experiencias sociales y políticas aún ocultas o silenciadas por el relato oficial de la historia diplomática.

Coincide así con la perspectiva de Der Derian, que en los años ochenta definió a la diplomacia como "la mediación del extrañamiento entre individuos, grupos o entidades"30, proponiendo un enfoque más abierto y dinámico del que había reinado hasta entonces. Puso en entredicho la clásica noción estatalista y enfatizó el proceso histórico de las múltiples mediaciones políticas, religiosas, filosóficas y sociales, demostrando al menos dos cosas: que es insuficiente estudiar la diplomacia como expresión de la soberanía del estado, y que la evolución occidental de la diplomacia supone un pasado diplomático complejo y sustancioso que se encuentra antes de la formación del sistema de estados europeos y, que además, sirve para explicar tanto la formación de la diplomacia moderna como la proyección futura de las mediaciones globales ${ }^{31}$. En consonancia con esto, reclama que los orígenes de la diplomacia no son ni cronológica ni geográficamente estáticos, sino imbuidos por la relación del espaciotiempo, de la cultura y del poder.

Costas Constantinou -en el mismo sentido de Der Derian- señaló que los enfoques convencionales de la diplomacia -asuntos intergubernamentales, gestión de relaciones interestatales, o negociación de los intereses nacionales-, son insuficientes para explicar la rica historia de la diplomacia y captar la complejidad del mundo diplomático contemporáneo. Constantinou afirmó que la diplomacia debería ser entendida en términos de "diplomacia humana", es decir, como una dimensión no profesional de las relaciones interpersonales de los "homo sapiens" que experimentan en un nivel no técnico, experimental y vivencial de la vida cotidiana32. Constantinou acuña el término "homo-diplomacia" para mostrar que la diplomacia humana es una forma más adecuada para comprender las formas alternativas de relacionamiento humano y su potencial posibilidad para transformar positivamente ciertas condiciones sociales, religiosas o políticas a través de la profunda alteridad. Parece que Constantinou discute las determinaciones hobbesianas de la diplomacia realista y acoge

\footnotetext{
${ }^{29}$ CORNAGO, Noé, Plural Diplomacies: Normative Predicaments and Functional Imperatives, Martinus Nijhoff Publishers, Boston, 2013, p. 2.

${ }^{30}$ DER DERIAN, James, On Diplomacy..., op.cit.

${ }^{31}$ Ibídem.

${ }^{32}$ CONSTANTINOU, Costas M., "On homo-diplomacy" en Space and Culture, vol. 9, no 4, 2006, pp. 351-364.
} 
un número plural de entidades —más allá del estado- que desarrollan las interacciones históricas.

Dichas reflexiones invitan a pensar la diplomacia como profunda alteridad, expresión de "un proceso regulado de comunicación"33 que se produce entre la identidad/diferencia por medio de la representación, intercambio y reciprocidad, y que son cristalizadas en procesos rituales y ceremoniales que forman reales códigos comunicativos de entendimiento, prototipos que no pueden confundirse, ni reducirse a la institucionalización y la profesionalización de la diplomacia. Como señaló Paul Sharp, la diplomacia "expresa una condición humana que precede y trasciende la experiencia de vivir en los Estados soberanos de los últimos siglos" ${ }^{\prime 34}$.

Como se viene indicando, la diplomacia no se reduce solo a los estados; para Der Derian, el problema de esta visión normativa es que suele apoyar acríticamente una visión teleológica de la diplomacia, sin explorar las fuerzas dinámicas que motivaron su necesidad en la historia ${ }^{35}$. En efecto, las ideas de estabilización de la diplomacia con embajadas permanentes y la profesionalización con diplomáticos formados en temas de negociación estratégica son una versión de la diplomacia moderna, pero no la única. A pesar de las múltiples transformaciones y las complejas expresiones de la diplomacia, ésta ha sido reducida a una narrativa singular y temporal que va desde la antigüedad hasta la moderna diplomacia estatal ${ }^{36}$, tal como lo enfatiza Cornago:

"En la actualidad el estudio convencional de la diplomacia suele excluir una amplia gama de prácticas, tales como la participación no gubernamental o la acción exterior de los gobiernos no centrales, a pesar de su creciente relevancia. Sin embargo se puede afirmar que la extendida consideración de la diplomacia como atributo exclusivo del estado soberano, constituye más la institucionalización de un discurso político que el corolario de una realidad"37.

En su conjunto, las posturas expuestas proponen una apertura y separación de las clásicas teorías que han definido la noción de diplomacia y su respaldo histórico. La sugerencia de otra narrativa diplomática se hace así necesaria a fin de mejorar la interpretación de la alteridad diplomática de nuestro tiempo.

\section{Mirada histórica I: el nacimiento de la diplomacia moderna}

El apartado anterior señaló que la diplomacia es una noción mucho más amplia y diversa que la considerada hasta ahora por la academia clásica. Su gran virtud es que genealógica y fenomenológicamente hace posible hablar de múltiples prácticas diplomáticas, aspecto que cada vez se ve más reflejado en la bibliografía contemporáneo sobre la diplomacia.

\footnotetext{
${ }^{33}$ CONSTANTINOU, Costas M., On the Way to Diplomacy, University of Minnesota Press, Minneapolis, 1996.

${ }^{34}$ SHARP, Paul, "For Diplomacy: Representation and the Study of International Relations" en International Studies Review, vol. 1, no 1, 1999, p. 51.

${ }^{35}$ Ibídem.

${ }^{36}$ CORNAGO, Noé, Plural Diplomacies..., op.cit.

${ }^{37}$ CORNAGO, Noé, "Diplomacia, paradiplomacia y redefinición de la seguridad mundial: dimensiones de conflicto y cooperación" en ALDECOA, Francisco y KEATING, Michael (eds.), Paradiplomacia: las relaciones internacionales de las regiones, Ediciones Marcial Pons, 2000, Madrid, p. 55-56.
} 
Sin embargo, este apartado se aproxima a ciertas prácticas diplomáticas que considero han sido invisibilizadas por el relato oficial y que podrían caracterizarse como "diplomacias de resistencia". Para ello, presentaré ejemplos que inician en el siglo XV y que se extienden hasta nuestro tiempo. Tomo estas fechas al afirmar que la versión diplomática obviada por el relato oficial adquiere un matiz diferente cuando se piensa desde la formación del sistema mundo moderno, especialmente, con la experiencia del "descubrimiento", conquista y posterior colonización de lo que andando el tiempo será denominado América ${ }^{38}$. Considero que la poca relevancia que esta experiencia histórica ha tenido en la teoría clásica sobre la práctica diplomática -como ha sido considerada en nuestra definición- impide comprender mejor la historia de la diplomacia y el papel que los subalternos han jugado en la producción de la alteridad global. Por esta razón, mostraré de manera general hechos históricos que develan la diplomacia en el trascurrir del sistema mundial. Tengo consciencia de que los hechos son arbitrarios y de que presentan saltos cronológicos importantes, pero dicho camino no se aleja del propósito de replantear la historia diplomática, al contrario, no hacen más que reforzarla e invitar a su reconstrucción y su replanteamiento. Considero que es una nueva agenda de trabajo lo que deviene de estas aproximaciones.

La mayoría de manuales sobre la cuestión fijan el nacimiento de la denominada "diplomacia moderna" en el Tratado de Westfalia (1648). Sin embargo, no considero apropiado mantener esta fecha como fundacional, ya que debería considerarse a este hecho como el surgimiento de la "intradiplomacia moderna europea", forjada como tecnología mundial de seguridad ${ }^{39}$, y desarrollada como "la secularización del discurso diplomático, la monopolización progresiva de la diplomacia por el estado-nación y el advenimiento de la razón de estado"40. El Tratado de Westfalia articuló las reglas de juego intraeuropeo sobre la base del control económico de los mercados y la expansión de las influencias políticas para la defensa de los intereses de cada entidad soberana. Según Michel Foucault, es en este momento cuando las nuevas guerras de cálculo abandonan la lógica medieval de la guerra justa y desarrollan un dispositivo diplomático-militar que permita alcanzar una balanza de fuerzas o una política de equilibrio intraeuropeo que mantenga la paz, en una suerte de sociedad de naciones que comparten un interés común ${ }^{41}$. Con ello podemos decir que se funda jurídicamente el pensamiento guerra-paz moderno, que contiene la definición de la diplomacia clásica.

Por el contrario, valdría la pena considerar que la diplomacia moderna, como hecho fundacional del sistema mundo moderno, nace a finales del siglo XV en las costas del Caribe, tras la primera mediación de extrañamiento a través del circuito atlántico. Me refiero, como ya se indicó previamente, al primer viaje diplomático que terminó más allá de las costas mediterráneas con las carabelas de La Pinta, La Niña y La Santamaría, y que forjó el inicio de nuestro tiempo planetario. En este viaje, Cristóbal Colón zarpó como enviado diplomático de los Reyes Católicos, acreditado por cartas credenciales o letras de creencia destinadas a

\footnotetext{
${ }^{38}$ WALLERSTEIN, Immanuel, El moderno sistema mundial I. La agricultura capitalista y los orígenes de la economíamundo europea en el siglo XVI, Siglo Veintiuno, Madrid, 2010; QUIJANO, Aníbal y WALLERSTEIN, Immanuel, "'Americanity' as a 'Concept'. Or the Americas in the Modern World" en International Social Science Journal, 1992, vol. 44, no 4, pp. 549-557.

${ }^{39}$ FOUCAULT, Michel, Seguridad, territorio, población, Fondo de Cultura Económica, Buenos Aires, 2006.

${ }^{40}$ CONSTANTINOU, Costas y DER DERIAN, James, Sustainable Diplomacies, Palgrave MacMillan, Nueva York, 2010, p. 6.

${ }^{41}$ FOUCAULT, Michel, Seguridad, territorio..., op.cit.
} 
monarcas extranjeros ${ }^{42} y$, no solamente fue el primero en salir "oficialmente con 'poderes' no siendo ya un viaje clandestino, como muchos de los anteriores - de la Europa latina antimusulmana, sino que fue el principio de la constitución de la experiencia existencial de una Europa Occidental, atlántica y 'centro' de la historia"43. Este primer proceso de mediación del extrañamiento construyó el primer relato incorporado a la narrativa dominante de alteridad mundial bajo la idea de un "ser-asiático":

"Se puede concluir que el significado histórico y ontológico del viaje de 1492 consiste en que se atribuyó a las tierras que encontró Colón el sentido de pertenecer al orbis terrarum, dotándolas así con ese ser, mediante una hipótesis a priori e incondicional"44.

Podría discutirse que antes de aquel momento, los procesos de invasión habían sido precedidos por prácticas diplomáticas similares, como ocurrió con el Imperio Romano, por ejemplo. Sin embargo, la gran diferencia reside en que solamente en esta embrionaria diplomacia se formará la consciencia moderna y se conectarán todas las porciones del mundo. El encuentro transformará definitivamente a "la Europa provinciana y renacentista, mediterránea, en la Europa 'centro' del mundo: en la Europa moderna"45, dando con ello inicio a las diplomacias del sistema mundo moderno.

La diplomacia medieval europea deviene moderna con la interacción ultramarina que le dota de una consciencia nueva y lanza a todos los continentes a una nueva época de alteridad. Los textos representativos de esta experiencia son la bula de Alejandro VI Inter Caetera (II), del 4 mayo de 1493, y el Tratado de Tordesillas, del 7 de junio de 1494.

La bula Inter Caetera (II) recoge la preocupación de los Reyes Católicos sobre el reconocimiento previo hecho por Castilla a Portugal en 1479 sobre la competencia exclusiva de la navegación desde las Canarias hacia el sur en busca de las indias orientales, problema que surgió al descubrir Colón nuevos territorios y tener los castellanos la sospecha de que Portugal podría reclamarlos como propios en base a dicho acuerdo. Isabel y Fernando solicitan del papa Alejandro VI una bula -el más solemne documento pontificio- para que les reconozca los nuevos territorios de "las indias orientales". El título otorgado por la bula papal confirió a los Reyes Católicos la seguridad sobre el dominio legítimo de los territorios descubiertos.

El segundo de los documentos antes indicados -el Tratado de Tordesillas - fue firmado entre Castilla y Portugal, y disipó el temor de los primeros sobre la posesión ilegal de los nuevos territorios. El Tratado de Tordesillas amplió la línea de demarcación para dividir el Atlántico de forma equivalente. A partir de entonces aparece un derecho emergente ${ }^{46}$ y

\footnotetext{
${ }^{42}$ OCHOA, Miguel, "La Diplomacia y el Descubrimiento de América" en CÉSPEDES, Guillermo, (coord.), Colón en el mundo que le tocó vivir, Real Academia de la Historia, Madrid, 2007.

${ }^{43}$ DUSSEL, Enrique, 1492. El encubrimiento del otro: hacia el origen del mito de la modernidad, Plural Editores, La Paz, 1994, p. 30.

${ }^{44}$ O'GORMAN, Edmundo, El proceso de la invención de América, Fondo de Cultura Económica, México D.F., 1998 , p. 8.

${ }^{45}$ DUSSEL, Enrique, 1492. El encubrimiento..., op.cit., p. 32.

${ }^{46}$ SCHMITT, Carl, El nomos de la tierra en el Derecho de Gentes al Jus Publicum europaeum, Centro de Estudios Constitucionales, Madrid, 1979.
} 
unas prácticas diplomáticas que suponen nuevos retos tanto a los conquistadores como a los conquistados. En adelante podemos hablar de una "diplomacia de conquista", primero, y una "diplomacia colonial", después.

Hay un extrañamiento original que ocurre cuando Cristóbal Colón llega a las islas del Caribe y que es resuelto de diferentes maneras, tal como cuenta el propio Colón: violencia, engaño, negociación. Del extrañamiento original o de la diplomacia inicial, se pasa a una diplomacia de conquista - corta, ambigua, tensa- que podemos representar por medio de dos prácticas diplomáticas: la surgida entre Moctezuma Xocoyotzin y Hernán Cortés (1519), y la de Atahualpa y Francisco Pizarro (1532). Ambas experiencias son hitos históricos sobre el verdadero encuentro de los europeos con dos de las más grandes e imponentes organizaciones sociales y políticas de la época - aztecas e incas-, experiencias diplomáticas constitutivas y representativas de la diplomacia moderna aunque, en rigor, no fueron las primeras, ya que Hernán Cortés venía haciendo alianzas con "otros indios" cuando iba camino a Tenochtitlán.

Como lo narra Hernán Cortés en las Cartas de Relación -particularmente en la segunda-, su camino y llegada a México-Tenochtitlán tiene un sentido tanto militar como diplomático. En la Carta, Cortés relata las batallas que libra, la alianza que forja con los tlaxcaltecas, los mensajeros, mensajes y embajadas aztecas que buscaron disuadirlo de llegar a la gran ciudad y el encuentro, contenidos, rituales y protocolos, con Moctezuma. El proceso contiene una riqueza de aspectos psicológicos, sociológicos, culturales y políticos que son olvidados por la historia de la diplomacia moderna, y que deberían ser considerados dentro del relato diplomático y fundacional del sistema mundial. La diplomacia de conquista se caracteriza porque en estos momentos los futuros conquistados todavía están bajo su propia soberanía. Por el contrario, con el asentamiento del Imperio de España y el de Portugal en las nuevas tierras da inicio el período colonial -que va hasta principios del siglo XIX - caracterizado por una diplomacia también colonial; en este período, no existe una soberanía propia y totalmente independiente de los territorios o los pueblos colonizados. En este periodo, aunque las luchas entre los invasores y los pueblos ancestrales no cesaron y el proceso violento se mantuvo e incluso se agudizó, la mayor estabilidad sociopolítica produjo nuevas codificaciones diplomáticas, la principal de las cuales fue la "negociación" dentro de la "soberanía imperial" y el "pactismo" con pueblos que no pudieron ser conquistados ${ }^{47}$.

Comencemos por el "pactismo" como práctica diplomática colonial. Los pueblos resistentes fueron un problema para la administración colonial ya que su fuerza subversiva los convertía en potenciales aliados de los enemigos de la corona española. Los espacios fuera de control se convertían en refugio de resistencia cultural y religiosa para esclavos prófugos y demás personas que eran consideradas delincuentes y renegados. Además, "regiones fronterizas libres agrupaban importantes núcleos de población que dejaban de ser clientes directos del mercado colonial, y cuyas actividades de transacción y contrabando quedaban fuera del control fiscal colonial" 48 . Dicha situación fue resuelta por medio de procesos diplomáticos que se tranzaban con la firma de pactos entre los pueblos indios y el Imperio

\footnotetext{
${ }^{47}$ LÁZARO, Carlos, Las fronteras de América y los "Flandes Indianos", Editorial CSIC - CSIC Press, Madrid, 1997.

${ }^{48}$ LÁZARO, Carlos, "Conquista, control y convicción: el papel de los parlamentos indígenas en México, el Chaco y Norteamérica" en Revista de Indias, vol. 59, n² 217, 1999, p. 645.
} 
español. Al principio de manera informal y luego como lenguaje de la administración política de la metrópoli, el pactismo se convirtió en una institución diplomática que duró más de un siglo.

La otra práctica diplomática colonial fue la conocida como "negociación" indígena. Fue usada por la corona para controlar sus intereses y, por parte de los indios, como estrategia de adaptación y resistencia. Pero, a diferencia del pactismo, la negociación se produjo dentro de la "soberanía imperial". Mientras el pactismo se utilizó con pueblos a los que no fue posible vencer, la negociación se presentó con pueblos ya vencidos. Ethelia Ruiz Medrano y Susan Kellogg han recopilado una serie de ensayos que investigan aspectos claves de la interacción de los representantes indígenas con los españoles ${ }^{49}$. Esta actividad se produjo sobre aspectos culturales, económicos y de participación política para la supervivencia, y se materializó con el uso estratégico de la representación indígena, las leyes imperiales y las alianzas con otros sectores de la sociedad colonial. Dichas relaciones diplomáticas de la colonia muestran el activo papel de los pueblos indios, quienes no fueron simplemente unos "derrotados-expectantes" de la historia colonial, sino actores vivos y constituyentes del sistema mundial. Ambos fenómenos diplomáticos mostraron el activo papel diplomático sobre el que se fundó y desarrolló la estructura colonial.

Muchas de las señales diplomáticas entre pueblos indios y colonizadores reposan en la historia de los tratados del Nuevo Mundo que se extendieron por centurias entre pueblos indios y gobiernos británicos, franceses, españoles, alemanes y portugueses. Los acuerdos y tratados fueron muchas veces negociaciones en términos de inequidad o iniciativas unilaterales, pero no por ello dejan de ser acuerdos diplomáticos que sirvieron como arma de resistencia, supervivencia y participación en el sistema colonial ${ }^{50}$.

Aunque la experiencia colonial fue diferente en otras partes del mundo, las prácticas diplomáticas siempre emergieron como supervivencia de los colonizados o como estrategia de control por los colonizadores. Por ejemplo, mientras en Australia se presentó una experiencia colonial sin reconocimiento alguno de autonomía indígena ${ }^{51}$, en Nueva Zelanda se firmó en 1840 el Tratado de Waitangi entre maorís y el Gobierno británico, reconociendo ciertas autonomías a los pueblos originarios. Situación similar ocurrió en Norteamérica, donde los administradores de la colonia británica entre 1533 y 1789 reconocieron a las tribus indias similar soberanía 52 .

Hay un largo proceso diplomático entre las colonias europeas y las naciones indias del norte de América53; las relaciones diplomáticas entre la Confederación Iroquesa -las seis

\footnotetext{
${ }^{49}$ RUIZ, Ethelia y KELLOGG, Susan (eds.), Negotiation Within Domination: New Spain's Indian Pueblos Confront the Spanish State, University Press of Colorado, Colorado, 2010.

${ }^{50}$ LANGTON, Marcia, Honour among Nations: Treaties and Agreements with Indigenous People, Melbourne University Press, Melbourne, 2004.

${ }^{51}$ Algunos trabajos: DE COSTA, Ravi, A Higher Authority: Indigenous Transnationalism and Australia, UNSW Press, Sydney, 2006; FOLEY, Gary, SCHAAP, Andrew y HOWELL, Edwina, The Aboriginal Tent Embassy: Sovereignty, Black Power, Land Rights and the State, Routledge, Londres, 2013; WILD, Stefen A., Rom: An Aboriginal Ritual of Diplomacy, Aboriginal Studies Press, Nueva York, 1986.

${ }^{5}$ LANGTON, Marcia, Honour among Nations..., op.cit.

${ }^{53}$ Algunas investigaciones sobre la diplomacia indiana norteamericana y sobre la Confederación Iroquesa: HAVARD,
} 
antiguas naciones indias-y alemanes, ingleses y franceses son casos bien documentados ${ }^{54}$. En los tiempos de la colonización, es reconocido el papel de los iroqueses como mediadores entre líderes indios y las colonias inglesas. Literalmente, cientos de tratados recuerdan y prueban la fuerte actividad iroquesa llevada a cabo con los Países Bajos, Francia e Inglaterra ${ }^{55}$ y, posteriormente, con Estados Unidos y Canadá, así con otras naciones indias. Incluso se reconoce cierta herencia de la Confederación Iroquesa en la constitución de Estados Unidos ${ }^{56}$.

En general, el nacimiento y formación de la diplomacia moderna debería tomar en cuenta estos fenómenos, que enseñaron a los representantes europeos a gestionar su actividad diplomática a lo largo y ancho del mundo colonial y a desarrollar su política de intervención colonial y su posterior diseño de la política exterior de sus estados nacionales. Por su parte, la experiencia diplomática de conquista y colonia es determinante para comprender las formas de resistencia de los pueblos y naciones ancestrales, así como las posteriores diplomacias que emergen dentro del orden mundial poscolonial. La historia diplomática tiene aquí un reto fascinante para profundizar el conocimiento sobre el desarrollo del sistema mundial.

\section{Mirada histórica II: diplomacias y globalizaciones}

Una redimensión de la historia diplomática moderna debería tomar en cuenta la historia fundacional del sistema mundo -como lo hemos enunciado- y esforzarse por hacer el seguimiento de dichos procesos hasta el presente. Esta continuidad no es objeto del presente artículo, pero la presentación de experiencias diplomáticas que están fuera del relato oficial, a pesar de los saltos cronológicos, resulta provechoso para el propósito marcado al inicio del documento. Se trata de evidenciar las múltiples prácticas diplomáticas que quedan marginadas, especialmente las que denominamos "diplomacias de resistencia" - o como se sugiere en la actualidad, "diplomacias desde abajo"-. Se exponen a continuación las diplomacias en las últimas décadas de nuestro tiempo.

En el pasado como ahora, diferentes actores han desarrollado una actividad política "al margen y más allá de las instituciones representativas del sistema político de los estados nación"57. En la actualidad, Ulrich Beck denomina a este fenómeno "subpolítica", un producto de la globalización "desde abajo", que tiene como objeto discutir las condiciones de una economía política de la incertidumbre, los problemas ambientales y la miseria humana ${ }^{58}$, circunstancias promovidas por la globalización "desde arriba".

La "globalización desde arriba" es un término que denuncia el uso "no-neutral" del significado de globalización. Boaventura de Sousa Santos habla de globalizaciones, en

Gilles, The Great Peace of Montreal of 1701: French-Native Diplomacy in the Seventeenth Century, McGill-Queen's Press - MQUP, Montreal, 2001; MIDTRØD, Tom Arne, The Memory of All Ancient Customs: Native American Diplomacy in the Colonial Hudson Valley, Cornell University Press, Nueva York, 2012.

${ }^{54}$ JENNINGS, Francis y FENTON, William N., The History and Culture of Iroquois Diplomacy: An Interdisciplinary Guide to the Treaties of the Six Nations and Their League, Syracuse University Press, Nueva York, 1995.

${ }^{55}$ AQUILA, Richard, The Iroquois Restoration: Iroquois Diplomacy on the Colonial Frontier, 1701-1754, University of Nebraska Press, Nebraska, 1983.

${ }^{56}$ YARROW, David The Great Law of Peace: New World Roots of American Democracy, Turtle EyeLand, The Unity of Biology and Ecology with Spirit, 1987.

${ }^{57}$ BECK, Ulrich, La sociedad del riesgo global, Siglo Veintiuno, Madrid, 2002, p. 61.

${ }^{58}$ Ibídem. 
plural, señalando dos tipos: una globalización desde arriba y otra desde abajo ${ }^{59}$. La primera es gestionada por una clase capitalista transnacional compuesta por un ala local y otra internacional, es decir, la gerencia del Estado y el impulso de grandes empresas privadas. La globalización desde arriba revela las alianzas de actores hegemónicos del sistema mundial quienes reproducen y gestionan las acciones y pautas económicas, políticas y culturales inspiradas en el neoliberalismo.

A su vez, el desarrollo de la economía producida por dichos sectores y clases "desde arriba" y sus instituciones, han generado un margen considerable de desigualdad económica y social, crisis financieras, políticas y sociales globales que impactan negativamente en la mayoría de la población. Dichas condiciones, que son además históricas, se han traducido prontamente en respuestas políticas, culturales y económicas por medio de alianzas populares transfronterizas, acciones de protesta conjuntas, encuentros transnacionales, etc., con el objetivo de enfrentar las imposiciones de la globalización desde arriba. Dichas respuestas son denominadas como "globalización desde abajo"60:

"las formas de dominación prevalecientes no excluyen la posibilidad de que los estados-nación subordinados, las regiones, las clases o grupos sociales y sus aliados, se organicen transnacionalmente en defensa de intereses percibidos como comunes y usen en su provecho las posibilidades para la interacción transnacional creadas por el sistema mundo. Tal organización está destinada a contrarrestar los efectos dañinos de las formas hegemónicas de globalización y se desarrolla a partir de la conciencia de las nuevas oportunidades de creatividad y solidaridad transnacionales, creadas por la intensificación de las interacciones globales"61.

La diplomacia desde abajo es una de las expresiones concretas que pertenecen a la globalización desde abajo. Pueblos y naciones sin estado, grupos sociales, actores no estatales, e incluso estados-nación subordinados, vienen desde décadas atrás desarrollando una práctica diplomática a través de las fronteras nacionales para incidir políticamente por medio del "cabildeo, la defensa y/o la negociación"62 en escenarios internacionales, regionales y nacionales. Esta forma de diplomacia ha servido para influenciar la adopción de normas internacionales de derechos humanos o medioambientales, crear consciencia en la comunidad internacional sobre situaciones particulares, presionar actores políticos en temas específicos y, en general, movilizar la voluntad para fortalecer sus demandas y propuestas. Además, es una diplomacia entre actores que comparten sus luchas y generan acuerdos, consensos, plataformas políticas, información y recursos financieros, técnicas y recursos humanos, posibilitando escenarios de aprendizaje y enfrentando los retos de la globalización de diversas maneras.

La diplomacia desde abajo abriga un conjunto de diplomacias, como son: la diplomacia

\footnotetext{
${ }^{59}$ RODRÍGUEZ, César y SANTOS, Boaventura de Sousa, Derecho y globalización desde abajo, Anthropos, Barcelona, 2007.

${ }^{60}$ Ibídem.

${ }^{61}$ SANTOS, Boaventura de Sousa, Sociología jurídica crítica: Para un nuevo sentido común en el derecho. ILSA Instituto Latinoamericano de Servicios Legales Alternativos, Bogotá, 2009, p. 274.

${ }^{62}$ Las tres figuras emulan a la diplomacia clásica pero tiene contenidos y fines diferentes.
} 
de los pueblos, diplomacia indígena, diplomacia popular, diplomacia ciudadana, diplomacia guerrillera, diplomacia de las ONG, diplomacia de la sociedad civil y muchas otras diplomacias ad hoc, o sostenidas, que son ejemplos de la emergente actividad diplomática no oficial contemporánea, que busca enfrentar la globalización desde arriba. Para explicar mejor estos aspectos de la diplomacia, veamos algunas de estas experiencias.

Comenzamos por la que quizá pueda ser la más parecida a la diplomacia clásica, la de los estados subordinados. Cabe destacar en este punto la diplomacia desarrollada por el estado -autodeclarado plurinacional- boliviano, de reciente refundación, que viene trabajando por formas de relacionamiento bajo la noción de la diplomacia de los pueblos, diferente de la diplomacia estatal-tradicional, y cuestiona la representación del estado-nacional al considerar que ha invisibilizado la pluralidad interna de pueblos y naciones. La diplomacia de los pueblos piensa en un doble sentido: hacia la descolonización de la vida estatal interna, y frente a las relaciones globales con otros pueblos, naciones, grupos, individuos y organizaciones del mundo. Asume, además, otros principios de integración y concepción de las relaciones internacionales, incorporando experiencia y saberes de los sectores marginados.

Jean Paul Guevara afirma que la diplomacia plurinacional supera la ciega defensa de la soberanía y los intereses nacionales. Tiene una función "proyectiva", entendida como la contribución a "proyectar nuevos modelos de cambio para la convivencia armónica a nivel internacional"63. Guevara afirma que la diplomacia de los pueblos es un nuevo enfoque no contemplado por las teorías de las relaciones internacionales; es producto de las luchas constituyentes que buscan refundar el estado-nacional boliviano y se fundamentan en las cosmovisiones, saberes y experiencias milenarias de los pueblos andinos. Normativa y prácticamente, este autor considera que la diplomacia de los pueblos significa

"escuchar, dialogar y trabajar para todos y no sólo para algunos sectores privilegiados... promover no sólo la relación entre Cancillerías sino entre pueblos, porque la savia de los procesos de integración y de cambio está en los pueblos... anteponer los derechos humanos y principios de la vida a la lógica del mercado y la inversión"64.

En este sentido, reafirma Karla Díaz que la diplomacia de los pueblos es un producto "de la epistemología del sur... que propone el paradigma del Buen Vivir - Sumak Kawsay o Suma Qamaña- como alternativa, y principalmente apunta hacia un nuevo tipo de integración, inclusiva, participativa y más arraigada en nuestras sociedades"65.

Una concepción de la diplomacia que, según esta autora, emerge de las luchas sociales contra el neoliberalismo en la región latinoamericana:

"se posicionan en el poder algunos gobiernos que persiguen profundas transformaciones en el estado y en las formas de hacer política. Especialmente desde Bolivia y Ecuador, pero también desde Venezuela se ha propuesto

\footnotetext{
${ }^{63}$ GUEVARA, Jean Paul, "Bolivia: procesos de cambio y política exterior" en Diplomacia, Estrategia, Política, no 8, oct.-dic. 2007, p. 36.

${ }^{64}$ Ibídem., p. 44.

${ }^{65}$ DÍAZ, Karla, "Diplomacia de los Pueblos, propuesta contra-hegemónica en las Relaciones Internacionales", en Revista Búsquedas Políticas, vol. 2, nº 1, 2013, p. 214.
} 
impulsar la Diplomacia de los Pueblos y la participación protagónica de los movimientos populares organizados en la construcción de un mundo pluripolar y en equilibrio como perspectiva de unión latinoamericana y caribeña"66.

Podríamos tomar otro ejemplo de diplomacia desde abajo que se fundamenta en saberes y prácticas ancestrales, pero en esta ocasión enfrentando al estado dentro de su propio territorio, como es el caso de Australia. En la celebración oficial del Australia Day, activistas indígenas plantaron una sombrilla de playa en el césped de Old Parliament House, en la ciudad de Canberra, en el año de 1972. Los indígenas colocaron un letrero que decía "Embassy", para protestar contra la nación australiana. Los indígenas rechazaron la declaración del Gobierno liberal McMahon, que discutía con violencia los derechos de los aborígenes a su tierra67. La Aboriginal Tent Embass' se fundó entonces, y se convirtió en un punto focal de protestas y marchas hacia el Parlamento, marcando un hito diplomático de reivindicación del derecho de autodeterminación de los pueblos ancestrales. La Aboriginal Tent Embassy quedó como referente de la conflictiva y tensa convivencia de soberanías y representaciones de pueblos y naciones dentro del territorio australiano. Asentada en la capital del país, esta embajada también se volvió un lugar de encuentro con australianos no indígenas y visitantes internacionales, para entablar diálogos y reflexiones sobre los derechos de autogobierno, control de territorios, derechos culturales, etc. La experiencia de la Aboriginal Tent Embassy se enfrentó por décadas a la diplomacia hegemónica.

Otra experiencia de la diplomacia desde abajo son las diplomacias que surgen de la ciudadanías, las ONG o la sociedad civil global conocida como la "diplomacia ciudadana", proveniente de ciudadanos que buscan prevenir, superar o resolver conflictos armados o violentos entre grupos o estados y/o entre ellos, o en temas de pobreza, exclusión social e inequidad68. Categorías como "diplomacia two track" o "diplomacia multitrack" son recurrentes para evocar este tipo de prácticas diplomáticas de la ciudadanía que persiguen el establecimiento de la paz internacional ${ }^{69}$. Asociada a los temas de seguridad o desigualdad social y política, la diplomacia ciudadana se ha convertido en una posibilidad en el tiempo de la globalización para

"promover agendas vinculadas a los bienes públicos globales, con especial énfasis en la construcción de la paz, la prevención de conflictos y la resolución pacífica de estos, y, a la vez, a superar el déficit democrático existente en el ámbito de las decisiones internacionales"70.

Esta visión de la diplomacia desde abajo se lleva adelante con más naturalidad en los movimientos sociales y las organizaciones políticas y sociales. El Congreso de los Pueblos

\footnotetext{
${ }^{66}$ Ibídem., p. 214.

${ }^{67}$ FOLEY, Gary, SCHAAP, Andrew y HOWELL, Edwina, The Aboriginal Tent Embassy: Sovereignty, Black Power, Land Rights and the State, Routledge, Londres, 2013.

${ }^{68}$ SERBIN, Andrés, Entre la confrontación y el diálogo, integración regional y diplomacia ciudadana, Siglo XXI, Buenos Aires, 2012.

${ }^{69}$ DIAMOND Louise y MCDONALD, John, Multi-track diplomacy: A systems approach to peace, Kumarian Press, West Hartford, 1996.

${ }^{70}$ Ibídem., p. 32-35.
} 
(Colombia), formado años atrás en un "proceso de carácter social y popular que convoca todas aquellas dinámicas y procesos de pueblos, sectores y regiones"71, reconoce que parte de su actividad está orientada a la diplomacia popular en busca de "recoger y fortalecer una agenda internacional para avanzar en la integración de los pueblos"; explica que no es posible construir una agenda de pueblos limitada a las fronteras colombianas, y encuentra necesario acercarse a otros pueblos y realidades, conocer sus agendas, sus propuestas, crear y compartirlas. El Congreso dice: "hay que juntarnos", y para ello sale y entra de su espectro político por medio de giras, participación en encuentros y reuniones de diplomacia popular: "las giras son una parte importante de la diplomacia popular que desarrolla el Congreso de los Pueblos con los pueblos del mundo" 72 .

La noción de diplomacia popular tiene raíces en el internacionalismo proletario que reafirmó una causa común más allá de las fronteras estatales, tal como quedó impreso en el Manifiesto Comunista: "proletarios de todos los países, uníos". Sin embargo, el Congreso de los Pueblos no es un partido político, ni un sindicato, es un proceso en el que convergen grupos que tienen identidades múltiples que aceptan una identidad más abierta y ambigua, la identidad de pueblo. Quizás por esto, más que hablar de diplomacia de los pueblos, la diplomacia popular se define de la siguiente forma:

"Como Congreso de los Pueblos reconocemos la urgente necesidad de conocer, reconocer, apoyar y aportar a los procesos populares de América Latina, y del mundo, con quienes compartimos formas de trabajo y luchas de emancipación; por esto, consideramos que es preciso establecer canales de comunicación y cooperación con estos procesos hermanos. El reconocimiento, el apoyo, el intercambio, la solidaridad, el trabajo local y el trabajo de visibilización en nuestros propios países de otras luchas, hacen parte de lo que denominamos Diplomacia Popular"73.

Estos breves ejemplos aquí descritos son parte del conjunto de prácticas diplomáticas contemporáneas promovidas por actores que luchan por una globalización contrahegemónica. La diplomacia desde abajo es un importante fenómeno global, amplio y de gran riqueza, que aún está por ser interpretado. Sin embargo, parece que está orientada por un principio axiológico que bien podríamos resumir así: unir en la diversidad, unificar sin uniformar, igualar sin borrar la identidad, mantener la diferencia sin jerarquizarla.

\section{Conclusión}

Es vital para las Relaciones Internacionales y los Estudios Diplomáticos encontrar renovados referentes para reinterpretar la historia signada en los manuales clásicos, y abrir sus perspectivas para conocer mejor la evolución del sistema mundial, reconociendo que la diplomacia, más que una anquilosada noción, resulta un campo de batalla tanto para la

\footnotetext{
${ }^{71}$ Ver la página oficial del Congreso de los Pueblos, "Objetivos", alojado en: http://congresodelospueblos.org/quesomos.html [Consultada el 3 de marzo de 2015]

${ }^{72}$ Ibídem.

${ }^{73}$ Esta afirmación es tomada de la página web oficial del Congreso de los Pueblos, "Gira del Congreso de los Pueblos en Europa construyendo diplomacia popular", se puede consultar en la siguiente dirección: http://congresodelospueblos. org/regiones/cp-europa/item/393-gira-del-congreso-de-los-pueblos-en-europa-construyendo-diplomacia-popular. html [Consultada el 3 de marzo de 2015]
} 
memoria subalterna como para la interpretación de la sociedad global contemporánea.

El presente artículo trató de abrir y ampliar dicha noción recurriendo al lugar de enunciación o posicionamiento político-intelectual, confrontando o cuestionando el eurocentrismo diplomático desde una plataforma de análisis e interpretación basada en diversas teorías y trabajos producidos dentro y fuera del campo diplomático, fundamentalmente desde la experiencia latinoamericana y del enfoque diplomático posmoderno.

Como se ha visto a lo largo del texto, los argumentos buscaron rivalizar con el relato eurocéntrico que dio forma a la historia de la diplomacia y para ello sugirió una transgresión subversiva de la historia universal de las relaciones internacionales. Para este propósito, fue importante tomar como ejemplos - con saltos cronológicos evidentes entre los casos, pero no por ello menos importantes - fenómenos que dieron forma y contenido al sistema mundial moderno, pero que fueron marginados por el relato oficial diplomático. Para una mejor reescritura de la historia diplomática sería necesario establecer una agenda de investigación, sin embargo, lo sugerido en este artículo debería ofrecernos una inquietud académica más crítica sobre la diplomática y menos marginal del papel que pueblos y naciones ancestrales, estados subordinados, grupos sociales, y actores sociales o políticos, tuvieron -y tienen- en la producción de la realidad planetaria en los ámbitos de la cultura, la política, la religión, la economía y el derecho.

Muchas de las diplomacias expuestas -y de las miles que aún debemos explorarevocan cosmovisiones, conocimientos, experiencias y prácticas que perviven en la exterioridad relativa del sistema mundial ${ }^{74}$, recordando que los procesos de colonización, neocolonización e imperialismo no exterminaron o eliminaron otras formas de gestionar la alteridad y vencer el extrañamiento original de quienes se vieron invadidos y dominados. En ese sentido, esta invitación no pretende ser solamente un enfoque descriptivo de novedosos fenómenos diplomáticos; es importante que el estudio diplomático sea provechoso para aportar a los procesos de resistencia venidos desde abajo por medio de la reflexión, la descripción, la interpretación, la crítica y el análisis.

El artículo toma recientes producciones académicas con una postura crítica sobre la noción de diplomacia que había sido condenada a una práctica profesional, técnica e interestatal basada en intereses casi exclusivamente nacionales. Los diálogos teóricos presentados muestran a la diplomacia como una categoría menos rígida y más abierta a la interpretación de fenómenos sociales y políticos, fundamentales para comprender las dinámicas entre lo local y lo global. Básicamente, estas posturas analíticas afirman que la diplomacia está implícita en la interacción humana y sugieren que la versión diplomática estatocéntrica es apenas una versión limitada.

La apuesta de este trabajo tiene una dimensión utópica sobre el sentido ontológico y axiológico de las interacciones humanas diplomáticas; privilegia el encuentro diplomático para enfrentar los conflictos, las tensiones y las ambigüedades sobre las que se desarrolla el

\footnotetext{
${ }^{74}$ La exterioridad relativa como la entiende Enrique Dussel al afirmar que la imposición de una nueva cultura occidental no logró exterminar finalmente la otredad.
} 
sistema mundial, pero sobre todo invoca un nuevo sentido de convivencia por medio de un espacio de negociación que reconoce, confronta y transforma las relaciones de desigualdad económicas y políticas. Por su sentido utópico y crítico, no pretende mejorar el sistema diplomático actual, sino subvertirlo, transformarlo, convertirlo en la posibilidad constituyente de un proyecto planetario más allá de la civilización occidental.

Las múltiples expresiones diplomáticas muestran la complejidad del sistema mundial y dejan entrever que tanto la historia de las relaciones internacionales como la teoría diplomática siguen en deuda con el objetivo de comprender la resistencia de los pueblos, su interacción para la supervivencia y el deseo de transformación proveniente del histórico pluralismo de la alteridad planetaria.

\section{Bibliografía}

AQUILA, Richard, The Iroquois Restoration: Iroquois Diplomacy on the Colonial Frontier, 1701-1754, University of Nebraska Press, Nebraska, 1983.

ARÉVALO ROBLES, Gabriel Andrés, "La diplomacia indígena: un enfoque transdiplomático" en Si Somos Americanos, vol. XVII, no 1, 2017, pp. 141-169: http://dx.doi.org/10.4067/S071909482017000100141 [Consultado el 31 de enero de 2018]

BECK, Ulrich, La sociedad del riesgo global, Siglo Veintiuno, Madrid, 2002.

BULL, Hedley, La sociedad anárquica: Un estudio sobre el orden en la política mundial, Los Libros de la Catarata, Madrid, 2005.

CONSTANTINOU, Costas M., On the Way to Diplomacy, University of Minnesota Press, Minneapolis, 1996.

CONSTANTINOU, Costas M., "On homo-diplomacy" en Space and Culture, vol. 9, no 4, 2006, pp. 351364.

CONSTANTINOU, Costas y DER DERIAN, James, Sustainable Diplomacies, Palgrave MacMillan, New York, 2010.

CORNAGO, Noé, "Diplomacia como heterología". Véase la publicación online alojada en la cuenta del autor en la plataforma académica academia.edu: https://www.academia.edu/4324372/La_ diplomacia_como_heterolog\%C3\%ADa [Consultado el 29 de octubre de 2013]

CORNAGO, Noé, "Diplomacia, paradiplomacia y redefinición de la seguridad mundial: dimensiones de conflicto y cooperación" en ALDECOA, Francisco y KEATING, Michael (eds.) Paradiplomacia: las relaciones internacionales de las regiones, Ediciones Marcial Pons, Madrid, 2000.

CORNAGO, Noé, Plural Diplomacies: Normative Predicaments and Functional Imperatives, Martinus Nijhoff Publishers, Boston, 2013.

DE COSTA, Ravi, A Higher Authority: Indigenous Transnationalism and Australia, UNSW Press, Sydney, 2006.

DER DERIAN, James, On Diplomacy: A Genealogy of Western Estrangement, Blackwell, Oxford, 1987.

DIAMOND, Louise y MCDONALD, John, Multi-track diplomacy: A systems approach to peace, Kumarian Press, West Hartford, 1996.

DÍAZ, Karla, "Diplomacia de los Pueblos, propuesta contra-hegemónica en las Relaciones Internacionales", en Revista Búsquedas Políticas, vol. 2, no 1, 2013, pp. 213-237: http://hdl. handle.net/11242/5125 [Consultado el 29 de mayo de 2014]

DUSSEL, Enrique, 1492. El encubrimiento del otro: hacia el origen del mito de la modernidad, Plural Editores, La Paz, 1994.

FOLEY, Gary, SCHAAP, Andrew y HOWELL, Edwina, The Aboriginal Tent Embassy: Sovereignty, Black Power, Land Rights and the State, Routledge, Londres, 2013.

FOUCAULT, Michel, Seguridad, territorio, población, Fondo de Cultura Económica, Buenos Aires, 2006.

GUEVARA, Jean Paul, "Bolivia: procesos de cambio y política exterior" en Diplomacia, Estrategia, Política, no 8, 2007, pp. 36-49.

HALLIDAY, Fred, Las relaciones internacionales en un mundo en transformación, Catarata, Madrid, 2002.

HAVARD, Gilles, The Great Peace of Montreal of 1701: French-Native Diplomacy in the Seventeenth Century, McGill-Queen's Press - MQUP, Montreal, 2001.

HOLSTI, Kalevi, Taming the Sovereigns: Institutional Change in International Politics, Cambridge University Press, Cambridge, 2004.

HURRE, Andrew, "Prólogo a la Tercera Edición de 'La Sociedad Anárquica' 25 años después" en BULL, 
Hedley, La sociedad anárquica: Un estudio sobre el orden en la política mundial, Los Libros de la Catarata, Madrid, 2005.

JENNINGS, Francis y FENTON, William N., The History and Culture of Iroquois Diplomacy: An Interdisciplinary Guide to the Treaties of the Six Nations and Their League, Syracuse University Press, Nueva York, 1995.

JONES, Branwen Gruffydd (ed), Decolonizing International Relations, Rowman \& Littlefield, Maryland, 2006.

JONES, Raymond, The British Diplomatic Service, 1815-1914, Wilfrid Laurier University Press, Ontario, 1983.

JÖNSSON, Christer, "Theorising Diplomacy" en MCKERCHER, Brian J. C. (ed.), Routledge Handbook of Diplomacy and Statecraft, Routledge, Londres, 2011.

KEOHANE, Robert, Después de la hegemonía: cooperación y discordia en la política económica mundial, Grupo Editor Latinoamericano, Buenos Aires, 1988.

KISSINGER, Henry, Diplomacy, Simon \& Shuster, Nueva York, 1994.

LANGTON, Marcia, Honour among Nations: Treaties and Agreements with Indigenous People, Melbourne University Press, Melbourne, 2004.

LÁZARO, Carlos, "Conquista, control y convicción: el papel de los parlamentos indígenas en México, el Chaco y Norteamérica" en Revista de Indias, vol. 59, no 217, 1999, pp. 645-673.

LÁZARO, Carlos, Las fronteras de América y los "Flandes Indianos", Editorial CSIC - CSIC Press, Madrid, 1997.

MIDTRØD, Tom Arne, The Memory of All Ancient Customs: Native American Diplomacy in the Colonial Hudson Valley, Cornell University Press, Nueva York, 2012.

NEUMANN, Iver B., "The English School on Diplomacy" en JÖNSON, Christer y LANGHORNE Richard (coords.), Theory of Diplomacy, Sage Publicaciones, Londres, 2004, pp. 96-116.

O’GORMAN, Edmundo, El proceso de la invención de América, Fondo de Cultura Económica, México D.F., 1998.

OCHOA, Miguel, "La Diplomacia y el Descubrimiento de América" en CÉSPEDES, Guillermo, (coord.), Colón en el mundo que le tocó vivir, Real Academia de la Historia, Madrid, 2007.

RODRÍGUEZ, César y SANTOS, Boaventura de Sousa, Derecho y globalización desde abajo, Anthropos, Barcelona, 2007.

ROSECRANCE, Richard, "Diplomacia" en Enciclopedia Internacional de Ciencias Sociales, Aguilar, Madrid, 1974.

RUIZ, Ethelia y KELLOGG, Susan (eds.), Negotiation Within Domination: New Spain's Indian Pueblos Confront the Spanish State, University Press of Colorado, Colorado, 2010.

SANTOS, Boaventura de Sousa, Sociología jurídica crítica: Para un nuevo sentido común en el derecho, ILSA Instituto Latinoamericano de Servicios Legales Alternativos, Bogotá, 2009.

SERBIN, Andrés, Entre la confrontación y el diálogo: integración regional y diplomacia ciudadana, Siglo XXI, Buenos Aires, 2012.

SHARP, Paul, "For Diplomacy: Representation and the Study of International Relations" en International Studies Review, vol. 1, no 1, 1999, pp. 33-57.

SHARP, Paul, Diplomatic Theory of International Relations, Cambridge University Press, Cambridge, 2009.

QUIJANO, Aníbal y WALLERSTEIN, Immanuel, "'Americanity' as a 'Concept'. Or the Americas in the Modern World" en International Social Science Journal, 1992, vol. 44, no 4, pp. 549-557.

WALLERSTEIN, Immanuel, El moderno sistema mundial I. La agricultura capitalista y los orígenes de la economía-mundo europea en el siglo XVI, Siglo Veintiuno, Madrid, 2010.

WATSON, Adam, Diplomacy: The Dialogue Between States, Psychology Press, Londres, 1982.

WIGHT, Martin, Power Politics, Continuum, Londres y Nueva York, 2002.

WILD, Stefen A., Rom: An Aboriginal Ritual of Diplomacy, Aboriginal Studies Press, Sydney, 1986.

YARROW, David, The Great Law of Peace: New World Roots of American Democracy, Turtle EyeLand, The Unity of Biology and Ecology with Spirit, 1987 


\section{RELACIONES INTERNACIONALES}

Revista académica cuatrimestral de publicación electrónica Grupo de Estudios de Relaciones Internacionales (GERI) Universidad Autónoma de Madrid, España

www.relacionesinternacionales.info

ISSN 1699 - 3950

ff facebook.com/RelacionesInternacionales

twitter.com/RRInternacional 